Atmos. Chem. Phys., 2, 235-247, 2002

www.atmos-chem-phys.org/acp/2/235/

\title{
The adsorption enthalpy of nitrogen oxides on crystalline ice
}

\author{
T. Bartels-Rausch ${ }^{1}$, B. Eichler ${ }^{1}$, P. Zimmermann ${ }^{1}$, H. W. Gäggeler ${ }^{1,2}$, and M. Ammann ${ }^{1}$ \\ ${ }^{1}$ Paul Scherrer Institute, CH-5232 Villigen PSI, Switzerland \\ ${ }^{2}$ University of Berne, CH-3012 Bern, Switzerland
}

Received: 22 February 2002 - Published in Atmos. Chem. Phys. Discuss.: 16 April 2002

Revised: 16 August 2002 - Accepted: 20 August 2002 - Published: 20 September 2002

\begin{abstract}
The partitioning of nitrogen oxides between ice and air is important to the ozone budget in the upper troposphere. In the present study, the adsorption of nitrogen oxides on ice was investigated at atmospheric pressure using a chromatographic technique with low concentrations of radioactively labelled nitrogen oxides. The measured retentions solely depended on molecular adsorption and were not influenced by dimerisation, formation of encapsulated hydrates on the ice surface, dissociation of the acids, nor by migration into a quasi-liquid layer or grain boundaries. Based on the chromatographic retention and the model of thermochromatography, the adsorption enthalpies of $-20 \mathrm{~kJ} \mathrm{~mol}^{-1}$ for $\mathrm{NO},-22 \mathrm{~kJ} \mathrm{~mol}^{-1}$ for $\mathrm{NO}_{2},-30 \mathrm{~kJ} \mathrm{~mol}^{-1}$ for peroxyacetyl nitrate, $-32 \mathrm{~kJ} \mathrm{~mol}^{-1}$ for $\mathrm{HONO}$ and $-44 \mathrm{~kJ} \mathrm{~mol}^{-1}$ for $\mathrm{HNO}_{3}$ were calculated. To assess the adsorption enthalpies, standard adsorption entropies were calculated based on statistical thermodynamics. In this work, the use of two different standard states was demonstrated. Consequently different values of the standard adsorption entropy, of either between $-39 \mathrm{~J}\left(\mathrm{~K} \mathrm{~mol}^{-1}\right.$ and $-45 \mathrm{~J}(\mathrm{~K} \mathrm{~mol})^{-1}$, or $-164 \mathrm{~J}(\mathrm{~K} \mathrm{~mol})^{-1}$ and $-169 \mathrm{~J}(\mathrm{~K} \mathrm{~mol})^{-1}$ for each nitrogen oxide were deduced. The adsorption enthalpy derived from the measurements, was independent of the choice of standard state. A brief outlook on environmental implications of our findings indicates that adsorption on ice might be an important removal process of $\mathrm{HNO}_{3}$. In addition, it might be of some importance for $\mathrm{HONO}$ and peroxyacetyl nitrate and irrelevant for $\mathrm{NO}$ and $\mathrm{NO}_{2}$.
\end{abstract}

\section{Introduction}

In the early 70's Crutzen (1970) stressed that nitrogen oxides play a critical role in the atmospheric ozone budget, e.g. in the upper troposphere where an increase in the $\mathrm{NO}_{\mathrm{x}}$ con-

Correspondence to: M. Ammann (markus.ammann@psi.ch) centration leads to higher ozone levels (Jaeglé et al., 1998). Therefore, detailed knowledge of the sources and sinks of nitrogen oxides in the atmosphere is of paramount importance in the understanding of the observed increase of ozone in the free troposphere (Wang et al., 1993) and to model the future composition of the atmosphere. Ice surfaces, which are one of the main condensed substrates in the upper troposphere and lower stratosphere (Winkler and Trepte, 1998; Heymsfield and Sabin, 1998), may be a powerful sink for $\mathrm{NO}_{\mathrm{y}}$. During the SUCCESS campaign, Weinheimer et al. (1998) measured $10 \%$ to $20 \%$ of the gas-phase $\mathrm{NO}_{\mathrm{y}}$ concentration in wave-cloud ice particles. Yet, for whatever uptake process of gas species on ice surfaces, the first step is adsorption on the surface. This study aims to evaluate the thermodynamics of adsorption for the reactive nitrogen species $\mathrm{NO}$ and $\mathrm{NO}_{2}$ and the reservoir species $\mathrm{HONO}, \mathrm{HNO}_{3}$ and peroxyacetyl nitrate (PAN) on ice surfaces. The thermodynamics of adsorption are rarely discussed in literature, as many of the previous studies have focused on uptake kinetics. To our knowledge, only few studies on $\mathrm{NO}, \mathrm{HONO}$ and $\mathrm{HNO}_{3}$ adsorption enthalpies on ice have been published (Sommerfeld et al., 1992; Rieley et al., 1996; Thibert and Dominé, 1998; Tabazadeh et al., 1999; Chu et al., 2000). We introduce here a method to simultaneously evaluate the adsorption properties of several $\mathrm{NO}_{\mathrm{y}}$ species in synthetic air on ice surfaces. The method combines the advantage of high sensitivity of a radioactive tracer technique with a chromatographic approach, thus enabled us to measure at atmospheric pressure and with a surface coverage of a fraction of a formal mono layer. Briefly, radioactively labelled nitrogen oxides in a flow of air or $\mathrm{N}_{2}$ are fed to a chromatographic column packed with ice spheres. A negative temperature gradient along the column leads to an increasing retention of each species as they are transported in the column. After the experiment, their migration distance in the column is determined by measuring the distribution of radioactivity along the column. If the model of mobile adsorption is applied, the adsorption en- 


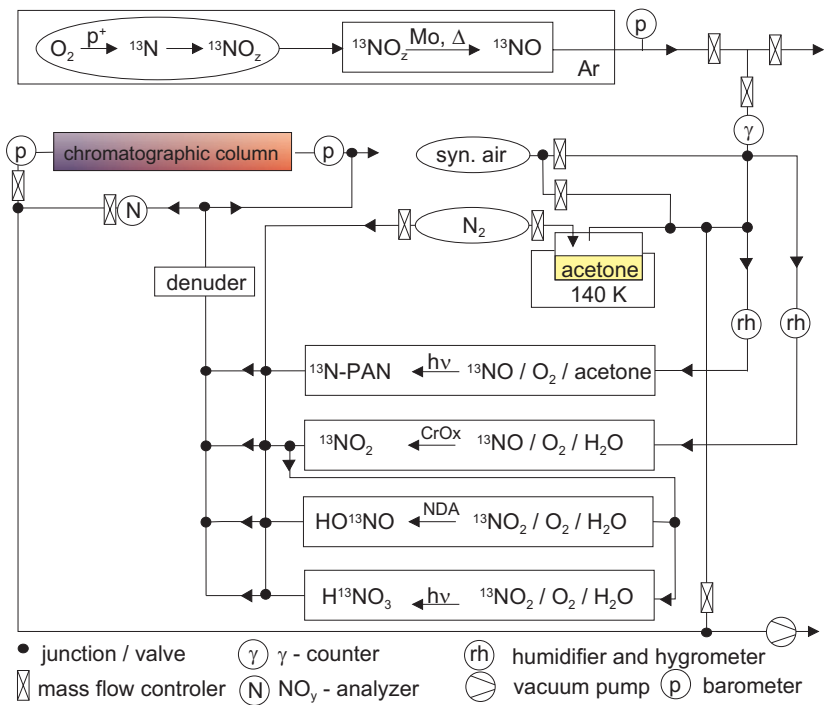

Fig. 1. Experimental set-up: gas target to produce ${ }^{13} \mathrm{~N}$, photolysis cells to oxidize the nitrogen oxides and chromatographic column.

thalpy can be calculated. Eichler et al. $(2000,1995)$ have shown the feasibility of this approach to derive the adsorption enthalpy of $\mathrm{NO}_{\mathrm{y}}$ on different surfaces and of radon on ice surfaces in previous studies. We will show here that the migration of the nitrogen oxides through the column is neither influenced by dimerisation, migration into a quasi-liquid layer or the grain boundaries, formation of encapsulated hydrates, nor by dissociation of the acids.

\section{Experimental}

\subsection{Gas phase synthesis}

Figure 1 shows the experimental set-up, which consists of the production of the radioactive nitrogen isotope ${ }^{13} \mathrm{~N}\left(\mathrm{t}_{1 / 2}=\right.$ $10 \mathrm{~min}$ ), the synthesis of various $\mathrm{NO}_{\mathrm{y}}$ species in designated reaction chambers, and the evaluation of their adsorption properties in the chromatographic apparatus. Details of the ${ }^{13} \mathrm{~N}$-production at Paul Scherrer Institute's Philips Cyclotron and the gas phase synthesis of ${ }^{13} \mathrm{NO}_{2}, \mathrm{HO}^{13} \mathrm{NO}$ and $\mathrm{H}^{13} \mathrm{NO}_{3}$ are described in detail elsewhere (Ammann, 2001). Briefly, a proton beam $(1 \mu \mathrm{A}, 11.1 \mathrm{MeV})$ irradiated a $5 \mathrm{~cm}^{3} \mathrm{~s}^{-1}$ flow of $20 \% \mathrm{O}_{2}(99.9995 \%$, Carbagas AG) in $\mathrm{He}(99.9999 \%$, Carbagas AG). This ${ }^{16} \mathrm{O}(\mathrm{p}, \alpha)^{13} \mathrm{~N}$ reaction formed various oxidized ${ }^{13} \mathrm{~N}$-species inside the gas target, which were reduced to ${ }^{13} \mathrm{NO}$ by passing them over a molybdenum foil at $300-500^{\circ} \mathrm{C}$. A $80 \mathrm{~m}$ long polyethylene tube $(2 \mathrm{~mm}$ in diameter) delivered the gas flow to the laboratory. This complete system was placed in a protective argon atmosphere (99.9999\% Carbagas AG) to prevent diffusion of impurities into the gas flow. In the laboratory, the gas flow passed a $\gamma$ counter to constantly evaluate the input of ${ }^{13} \mathrm{~N}$. Afterwards a fraction of the gas flow was diluted with $\mathrm{N}_{2}(99.9995 \%$, Carbagas AG) or synthetic air and fed to the experiments and a chemiluminescence NO analyzer (CLD, Germany). A molybdenum converter for reduction of $\mathrm{NO}_{\mathrm{y}}$ to $\mathrm{NO}$ was attached to the chemiluminescence analyzer to measure impurities of ${ }^{14} \mathrm{NO}_{\mathrm{y}}$, which come from irradiation of traces of ${ }^{14} \mathrm{~N}_{2}$ in the He- and $\mathrm{O}_{2}$-gas by the proton beam. All tubing in the laboratory was kept at room temperature and consisted of perfluoro-alkoxy copolymer (PFA) $4 \mathrm{~mm}$ i.d. without any protective gas surrounding them. The diffusion of impurities into the gas flow through PFA, as well as losses and memory effects of the various nitrogen oxides through the column walls are minimal compared to Teflon or polyethylene tubing (Neuman et al., 1999). The experiments were done at atmospheric pressure, and gas flows were controlled by mass flow controllers (Brooks Instruments, The Netherlands) with $1 \%$ full scale accuracy.

${ }^{13} \mathrm{NO}_{2}$ was synthesized by passing the ${ }^{13} \mathrm{NO}$ over $\mathrm{CrO}_{3}$ on firebrick support at $30 \%$ relative humidity. $\mathrm{HO}^{13} \mathrm{NO}$ was synthesized by passing the ${ }^{13} \mathrm{NO}_{2}$ through a filter impregnated with $100 \mu \mathrm{l}$ of $1 \% \mathrm{~N}$-(1-naphthyl)ethylenediamine dihydrochloride (NDA) in methanol-water (10/90) at 30\% relative humidity. $\mathrm{H}^{13} \mathrm{NO}_{3}$ was produced by photolysis of a ${ }^{13} \mathrm{NO}_{2} / \mathrm{H}_{2} \mathrm{O} / \mathrm{O}_{2}$ mixture in $\mathrm{N}_{2}$ at $172 \mathrm{~nm} .{ }^{13} \mathrm{~N}-$ PAN was produced through photolysis of acetone at $253 \mathrm{~nm}$ in the presence of ${ }^{13} \mathrm{NO}$ and $\mathrm{O}_{2}$ (Warneck and Zerbach, 1992). The acetone was dosed to the gas phase by passing a gentle flow of air over solid acetone at $140 \mathrm{~K}$. This saturated gas flow was further diluted prior to entering the photolysis cell. It is very important to work with low acetone concentrations, as in experiments with higher acetone concentrations, the acetone condensed on the ice and column walls, trapping the ${ }^{13} \mathrm{~N}-\mathrm{PAN}$, and consequently hindering its migration. This condensation, which is visible with the naked eyes, was not observed in the experiments described here with the low acetone concentration.

Most syntheses produced a mixture of several ${ }^{13} \mathrm{NO}_{\mathrm{y}}$ which, when fed to a column, yielded the adsorption properties of several ${ }^{13} \mathrm{NO}_{y}$ species simultaneously. To carry out experiments with only one ${ }^{13} \mathrm{NO}_{\mathrm{y}}$ species in the gas phase, a series of selective gas traps were used to scrub all but one species from the gas phase, where possible. The traps, which were designed as cylindrical denuders, were coated with $\mathrm{Na}_{2} \mathrm{CO}_{3}$ for absorbing $\mathrm{HONO}$ or PAN, a mixture of NDA and $\mathrm{KOH}(1 / 1)$ for $\mathrm{NO}_{2}, \mathrm{NaCl}$ for $\mathrm{HNO}_{3}$ and $\mathrm{Co}_{2} \mathrm{O}_{3}$ for NO (see Kalberer et al., 1996, 1999, for details). Those denuders, in combination with $\gamma$-detectors and the chemiluminescence $\mathrm{NO}_{\mathrm{y}}$ analyzer, were also used to identify and quantify the various ${ }^{13} \mathrm{NO}_{\mathrm{y}}$ species (Ammann, 2001). In addition, PAN was identified in the gas flow with a GC-ECD (Schrimpf et al., 1995). 


\subsection{Ice preparation and characterization}

Deionized water was purified with a Millipore Milli-Q water system to a resistivity $\leq 0.054 \mu \mathrm{S} \mathrm{cm}^{-1}$ and degassed in an ultra-sonic bath. Small droplets, $0.3-0.7 \mathrm{~mm}$ in diameter, were rapidly frozen in liquid nitrogen. The surface area of the ice spheres was evaluated based on the weight of 100 droplets and an ice density of $0.85 \mathrm{~g} \mathrm{~cm}^{-3}$. This low ice density was chosen to account for any air inclosure during the rapid freezing. The spheres were annealed in air for at least $12 \mathrm{~h}$ at $258 \mathrm{~K}$ in a cold room to allow them to crystallize. To prepare a column, the ice spheres were sieved with calibrated sieves (Retsch, Germany) with a grain size of $400 \mu \mathrm{m}$ and $630 \mu \mathrm{m}$. The spheres were filled in quartz, Teflon or PFA tubes, which were sealed at each end and stored at $258 \mathrm{~K}$. From the mass of the ice filling and the surface area per gram, the surface area per centimeter of the column was calculated, which varied between 4 and $10.9 \mathrm{~cm}^{2} \mathrm{~cm}^{-1}$ for the different experiments. During transport to the laboratory, the ice columns were cooled to $190 \mathrm{~K}$ with solid $\mathrm{CO}_{2}$. Additionally, a BET methane adsorption isotherm of the ice spheres was measured (Legagneux et al., 2002). In brief, approximately $66 \mathrm{~g}$ of the ice spheres, between $400 \mu \mathrm{m}$ and $500 \mu \mathrm{m}$ in diameter, were put in a sample holder in the cold room at $253 \mathrm{~K}$. The sample holder was placed in a cooled dewar, connected to the instrument in the laboratory at room temperature and immediately immersed in liquid nitrogen. The sample holder was then evacuated and subsequently dosed with methane at relative pressures between 0.007 and 0.22 to derive the adsorption isotherm. The relative pressure is equal to $\mathrm{p}_{\mathrm{i}} / \mathrm{p}^{\text {sat }}$ where $\mathrm{p}_{\mathrm{i}}[\mathrm{Pa}]$ is the absolute pressure and $\mathrm{p}^{\text {sat }}[\mathrm{Pa}]$ is the saturation pressure. The free volume of the filled sample holder was measured with He prior to the measurement.

\subsection{Thermo-chromatography}

The main feature of thermo-chromatography is a negative temperature gradient along the packed ice chromatography column. The apparatus is set up to maintain a stable and negative temperature gradient as shown in Fig. 2. It consists of a copper tube $(10 \mathrm{~mm}$ i.d.), the two ends of which were kept at different temperatures. One end, from which the gas flow exits the apparatus, was immersed in liquid nitrogen. The other end was cooled to a variable temperature between $218 \mathrm{~K}$ and $250 \mathrm{~K}$ with a cryostat. We used a Haake Phoenix P2-C50P thermostat or a Julabo FP88 with pure ethanol (Merck, 99\%) as cooling liquid. The cooling liquid was pumped through a copper tubing ( $8 \mathrm{~mm}$ i.d.), which was wound around the warmer end of the central copper tube bearing the ice column. The temperature at any position in the column was stable $( \pm 1 \mathrm{~K})$ after $1 \mathrm{~h}$ of operation. Prior to each experiment the temperature gradient was measured with a Pt-100 thermo element (MTS, Switzerland) in an empty column. The temperature gradient measurement in an empty column and a packed column showed good agreement. Depending

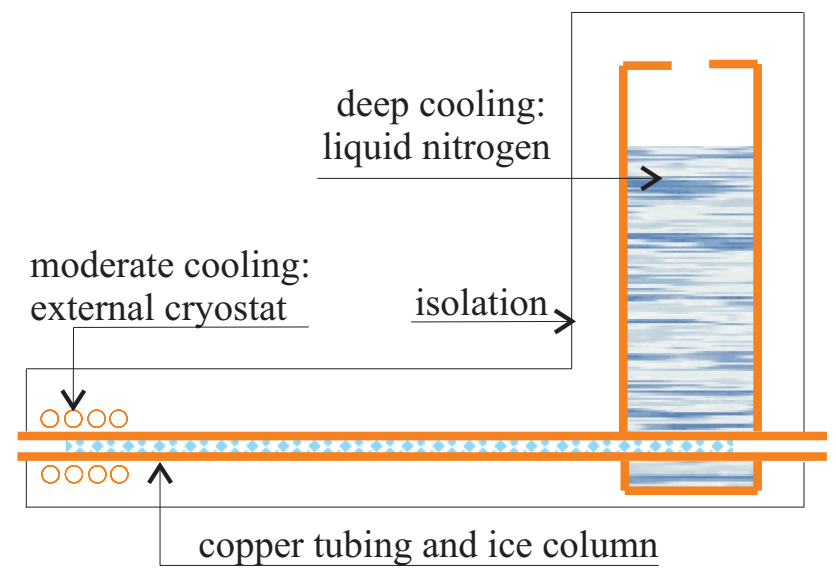

Fig. 2. Thermo-chromatography apparatus to maintain a negative temperature gradient along the column.

on the temperature at the column entrance and the length of the copper tube, a temperature gradient between $-4 \mathrm{~K} \mathrm{~cm}^{-1}$ and $-8 \mathrm{~K} \mathrm{~cm}^{-1}$ was measured. A typical temperature profile in the column is shown in Fig. 5. It is characterized by a flat temperature gradient at the beginning and at the end of the tube and by a steep gradient in the center part of the column. Only the slope of the central gradient, which is linear with a regression coefficient above 0.99 , was considered in our analysis. This is justified by the strong temperature dependence of the partition coefficient. For the error analysis, the slope of the temperature gradient was deduced only a few centimeters in front of a peak (see Sect. 3.3). Both gradients differed typically by $0.5 \mathrm{~K} \mathrm{~cm}^{-1}$.

To start an experiment the packed columns were placed in the temperature gradient. First, the carrier gas passed through the column for $30 \mathrm{~min}$. to allow the temperature equilibrium to be reached at any place in the ice column. Then, a small gas flow containing the ${ }^{13} \mathrm{~N}$-nitrogen oxides was added to the carrier gas. The concentration of nitrogen oxides was varied between $3 \mathrm{ppb}$ and $47 \mathrm{ppb}$. The flow through the column was controlled with a mass flow controller at the column exit and varied between $75 \mathrm{~cm}^{3} \mathrm{~min}^{-1}$ and $360 \mathrm{~cm}^{3} \mathrm{~min}^{-1}$. After a variable time of 14,30 or $31 \mathrm{~min}$ the experiment was stopped. The column was sealed and immersed in an open bath of liquid nitrogen to stop any further migration of nitrogen oxides in the column. The distribution of the ${ }^{13} \mathrm{~N}$-nitrogen oxides in the column was measured, usually exhibiting distinct, symmetric peaks for each $\mathrm{NO}_{\mathrm{y}}$ species. The migration distance, or more precisely, the temperature at this position (denoted as deposition temperature) is the primary observable of the experiment.

\subsection{Detection}

To deduce the distribution of nitrogen oxides along the column, a coincident $\gamma$-counter scanned each column three 
times. The coincident $\gamma$-counter consisted of two BismuthGermanate-detectors, $3 \mathrm{~cm}$ in diameter, mounted face to face with a gap of $35 \mathrm{~mm}$. Coincident $\gamma$-counting leads to optimum counting efficiency and low background counting rates (less than $1 \mathrm{cts} \mathrm{s}^{-1}$ ), because each decay of ${ }^{13} \mathrm{~N}$ results in two $\gamma$-rays in opposite directions to each other. The activity in the column was calculated based on the measured coincident counts and the radioactive decay after the experiment.

To determine the optimum step size of the detectors, the resolution and absolute efficiency of the system, a column was spiked with point- and broader sources of $\mathrm{a}^{18} \mathrm{~F}^{-}$solution of known activity and scanned. The optimum step size turned out to be $0.5 \mathrm{~cm}$, which yielded an accuracy in detection of the peak maximum position of $\leq 0.5 \mathrm{~cm}$. The resolution of this arrangement was $3 \mathrm{~cm}$, which led to a broadening of the peak base width to $4-6 \mathrm{~cm}$ of a point source of $\leq 0.5 \mathrm{~cm}$ in diameter. The absolute detector efficiency, which is defined as number of observed coincident counts per decay within $1 \mathrm{~cm}$, was 0.0134 . The efficiency of 0.0134 resulted in a detection limit of $1 \times 10^{5}$ molecules ${ }^{13} \mathrm{~N}$, or $8 \times 10^{-14} \mathrm{~mol}$ of total $\mathrm{NO}_{\mathrm{y}}\left({ }^{13} \mathrm{~N}+{ }^{14} \mathrm{~N}\right)$ per centimeter column length.

\subsection{Derivation of the adsorption enthalpy}

The adsorption enthalpy was calculated based on the experimentally determined migration distance and the theory of thermo-chromatography (Eichler and Zvára, 1982). This theory is based on the model of linear chromatography, which requires reversibility of the partition equilibria in the column. This reversibility has been demonstrated by Eichler et al. (1995) by simulating the experimentally observed deposition zone of $\mathrm{NO}_{2}$ by means of a Monte Carlo simulation exclusively based on a reversible equilibrium. A brief outline of the calculations, which were done with the Maple 6.0 software (Waterloo Maple), is given below. The detailed formulas and notations are given in the Appendix.

The model of linear chromatography (Eq. 1) describes the position of each species in the column, $z[\mathrm{~cm}]$, as function of the time, $t[\mathrm{~min}]$, the linear gas velocity, $u\left[\mathrm{~cm} \mathrm{~min}^{-1}\right]$ and the partition function, $k_{i}[-]$.

$$
\frac{\mathrm{d} z}{\mathrm{~d} t}=\frac{u}{1+k_{i}}
$$

Substituting $\mathrm{k}_{\mathrm{i}}$ with its thermodynamic definition and applying several simplifications (see Appendix B), Eq. (2) is obtained. It gives a relation between known experimental factors: $t_{\mathrm{e}}$ (experimental time), $g$ (temperature gradient), $u_{0}$ (linear gas velocity at standard temperature), $T_{\mathrm{D}}$ (deposition temperature), $T_{\mathrm{S}}$ (starting temperature of gradient), $v$ (open volume in the column), $a$ (ice surface area in column) and the thermodynamic functions $\Delta H_{\mathrm{ads}}$ (adsorption enthalpy), $\Delta S_{\text {ads }}^{0}$ (standard adsorption entropy), $T_{0}$ (standard temperature), $V / A$ (standard volume to standard surface area), $R$
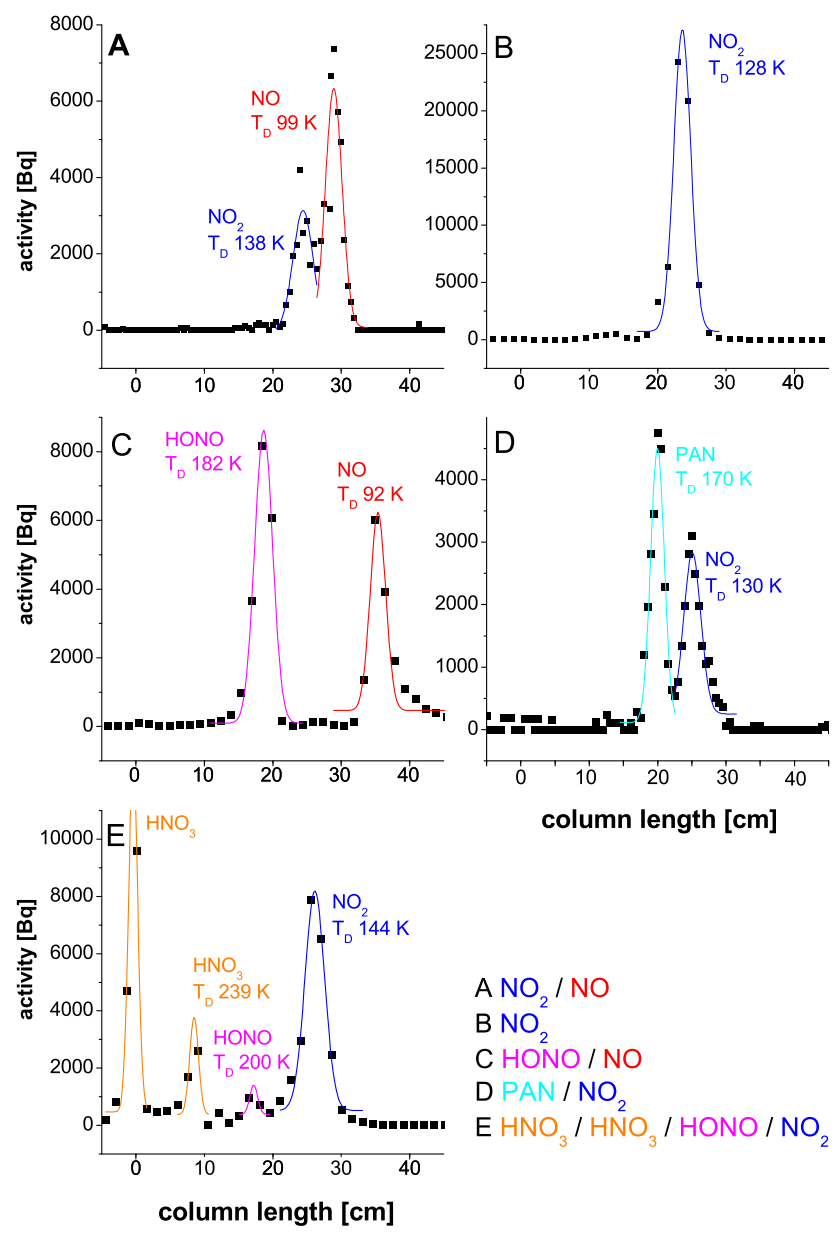

Fig. 3. Distribution of different nitrogen oxide species in columns packed with ice spheres at different experimental settings. Zero column length denotes the beginning of the ice spheres in the column. The activity is a measure for the concentration of $\mathrm{NO}_{\mathrm{y}}$ species along the column. The lines are Gaussian peak fits to our data by Origin 6.1. They are a help to visualize the results more easily. The spontaneous signals visible at the column entrance in chromatogram D are due to detector noise, and their decreasing relative contribution derives from the calculation of the activity based on the observed counts.

(gas constant).

$$
\begin{aligned}
\left(t_{\mathrm{e}}\right. & \left.+\frac{T_{0}}{g \cdot u_{0}} \cdot \ln \frac{T_{\mathrm{D}}}{T_{\mathrm{S}}}\right) \cdot \frac{v \cdot g \cdot u_{0}}{a \cdot T_{0} \cdot \frac{V}{A} \cdot \exp \left(\frac{\Delta S_{\text {ads }}^{0}}{R}\right)} \\
& =\int_{T_{\mathrm{S}}}^{T_{\mathrm{D}}} \frac{1}{T} \cdot \exp \left(\frac{-\Delta H_{\mathrm{ads}}}{R T}\right)
\end{aligned}
$$

For each set of experimental parameters, $\Delta \mathrm{H}_{\mathrm{ads}}$ was calculated by means of an iteration process with a given $\Delta S_{\text {ads }}^{0} . \Delta S_{\text {ads }}^{0}$ was calculated based on statistical thermodynamics and the model of mobile adsorption using Eq. (3) with $h$ (Planck constant), $k_{\mathrm{B}}$ (Boltzmann constant), $N_{\mathrm{A}}$ (Loschmidt's number), $m$ (molar mass) and $v$ (vibrating fre- 
quency) of the adsorbed species on the surface (see Appendix D). This frequency was assumed to be identical to the phonon frequency of ice. As to our knowledge no experimental data about the phonon frequency $v$ of the solid state of water at temperatures of our experiment exist, a rounded value of $3 \times 10^{13} \mathrm{~s}^{-1}$ based on the relations of Madelung and Einstein, Lindemann and Debye and data in Hobbs (1974, p. 388) was used (Eichler et al., 2000).

$$
\begin{aligned}
\Delta S_{\mathrm{ads}}^{0} & =R\left[\ln \left[\frac{A}{V} \sqrt{\frac{N_{\mathrm{A}} h^{2}}{2 \pi m k_{\mathrm{B}} T_{\mathrm{D}}}}\right]-0.5\right] \\
+R & {\left[\frac{h v}{k_{\mathrm{B}} T_{\mathrm{D}}\left(e^{\frac{h v}{k_{\mathrm{B}} T_{\mathrm{D}}}}-1\right)}\right] }
\end{aligned}
$$

\section{Results and discussion}

Figure 3 shows the chromatograms of various nitrogen oxides at low ppb concentrations in ice columns at different experimental settings. Chromatogram A results from exposure of the ice column to $\mathrm{NO}_{2}$ (peak at $24 \mathrm{~cm}$ ) and $\mathrm{NO}(29 \mathrm{~cm})$, $\mathrm{B}$ from exposure $\mathrm{NO}_{2}(24 \mathrm{~cm})$ with some traces of HONO $(13 \mathrm{~cm}), \mathrm{C}$ from HONO $(18 \mathrm{~cm})$ and $\mathrm{NO}(35 \mathrm{~cm}), \mathrm{D}$ from PAN $(20 \mathrm{~cm})$ and $\mathrm{NO}_{2}(25 \mathrm{~cm})$, and $\mathrm{E}$ from $\mathrm{HNO}_{3}(0 \mathrm{~cm}$ and $8 \mathrm{~cm})$, HONO $(18 \mathrm{~cm})$ and $\mathrm{NO}_{2}(26 \mathrm{~cm})$. It can be clearly seen that each nitrogen oxide species is uniquely retarded in the ice column leading to well defined chromatographic peaks, even if several species are fed to the column simultaneously. The surface concentration of $\mathrm{NO}_{\mathrm{y}}$ was always at least one order of magnitude below a mono layer even after accumulation for $30 \mathrm{~min}$. For example, a typical experiment with $4 \mathrm{ppb}$ of $\mathrm{NO}_{2}$ and $\mathrm{HONO}$ at a flow rate of $95 \mathrm{ml} \mathrm{min}^{-1}$ yielded a surface coverage of $1 \%$ of a formal mono layer for each nitrogen oxide at the end of an experiment. The experimental time of this run was $30 \mathrm{~min}$, the surface area per centimeter in the column was $10.9 \mathrm{~cm}^{2} \mathrm{~cm}^{-1}$ and the deposition temperature was $139 \mathrm{~K}$ and $184 \mathrm{~K}$, respectively. Peak base widths of $2 \mathrm{~cm}$ for the $\mathrm{NO}_{2}$ and $1 \mathrm{~cm}$ for the $\mathrm{HONO}$ peak and a formal mono layer of $1 \times 10^{15}$ molecules $\mathrm{cm}^{2}$ were assumed. Even at concentrations of $47 \mathrm{ppb} \mathrm{NO}_{\mathrm{y}}$, surface coverage did not exceed $13 \%$ of a formal mono layer at a flow rate of $27 \mathrm{ml} \mathrm{min}^{-1}$. Hence, condensation was very unlikely in the column. In addition, a concentration dependence of the migration distance between $3 \mathrm{ppb}$ and $47 \mathrm{ppb} \mathrm{NO}_{\mathrm{y}}$ in the gas phase was not observed, as expected for condensational processes.

3.1 Mechanistic considerations of the uptake at experimental conditions

To evaluate chromatographic experiments, it is absolutely mandatory to know which processes occur in the column and

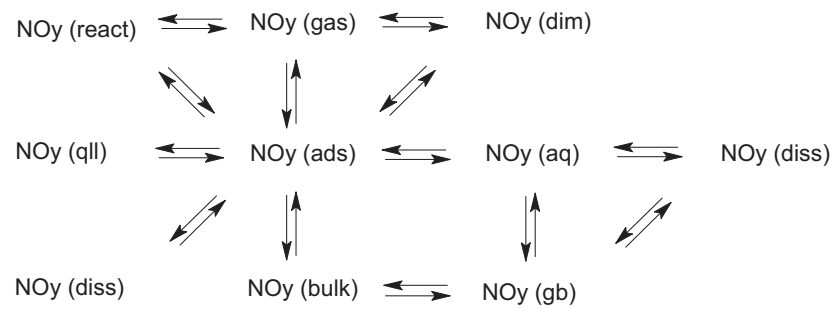

Fig. 4. Overview of equilibria of nitrogen oxides in the gas and ice phase, such as dimerisation (dim), e.g. $\mathrm{NO}_{2} \rightleftharpoons \mathrm{N}_{2} \mathrm{O}_{4}$; adsorption (ads); reaction (react), e.g. $\mathrm{NO}_{2}+\mathrm{NO} \rightleftharpoons \mathrm{N}_{2} \mathrm{O}_{3}$; solvation into the quasi-liquid layer (qll), bulk or grain boundaries (gb); formation of encapsulated hydrates (aq); and dissociation (diss), e.g. of $\mathrm{HNO}_{2}$ and $\mathrm{HNO}_{3}$.

determine the retention behavior. The mechanistical aspects of uptake on ice are still under some debate (see Girardet and Toubin, 2001, for a detailed overview). Several possible mechanisms that can be advanced to describe the processes in the chromatographic column are summarized in Fig. 4. As the experimental set-up used in this work can not address the elementary processes in the column, in the following, published data were used to evaluate which process might determine the retention. The importance of such analysis has been shown by Huthwelker et al. (2001), who reanalyzed data of Lamb and Clapsaddle (1989) and Conklin et al. (1993). In this reanalysis the authors found, in contrast to the original publications, that the retention of $\mathrm{SO}_{2}$ in these experiments on adsorption on ice was not due to adsorption, but to diffusion into the grain system of the polycrystalline ice.

The first question is, whether $\mathrm{NO}_{2}$ is dimerized, as it tends to at low temperatures, or reacted with $\mathrm{NO}$ to form $\mathrm{N}_{2} \mathrm{O}_{3}$ either in the gas phase or on the surface. For the following discussion, it was assumed that the adsorption equilibrium constant describes the partitioning of $\mathrm{NO}_{2}$ in the column, and a typical gas phase concentration of $3 \mathrm{ppb} \mathrm{NO}_{2}$ and flow rate of $5 \mathrm{~cm}^{3} \mathrm{~s}^{-1}$ were chosen. The concentration of $\mathrm{NO}_{2}$ first increases due to the temperature decrease at constant pressure up to its maximum value of about $1.3 \times 10^{11}$ molecules $\mathrm{cm}^{-3}$ at $140 \mathrm{~K}$, before it decreases rapidly due to the increasing residence time on the surface. Under these conditions (Atkinson et al., 1999), the extrapolated apparent first order forward rate constant for formation of $\mathrm{N}_{2} \mathrm{O}_{4}$ in the gas phase (Eq. 4) constantly increases from $5 \times 10^{-2} \mathrm{~s}^{-1}$ at $250 \mathrm{~K}$ to $1.4 \times 10^{-1} \mathrm{~s}^{-1}$ at $140 \mathrm{~K}$ and decreases again to $10^{-2} \mathrm{~s}^{-} 1$ at $120 \mathrm{~K}$.

$2 \mathrm{NO}_{2}($ gas $) \rightleftharpoons \mathrm{N}_{2} \mathrm{O}_{4}($ gas $)$

Obviously, the formation of $\mathrm{N}_{2} \mathrm{O}_{4}$ is much slower than the transport of $\mathrm{NO}_{2}$ in the carrier gas flow, which is almost constant at $0.02 \mathrm{~s}$ per cm column length from the column entrance to a position in the column at $140 \mathrm{~K}$. Thus, under the non-steady-state conditions of this chromatographic system the dimerisation is very unlikely. 


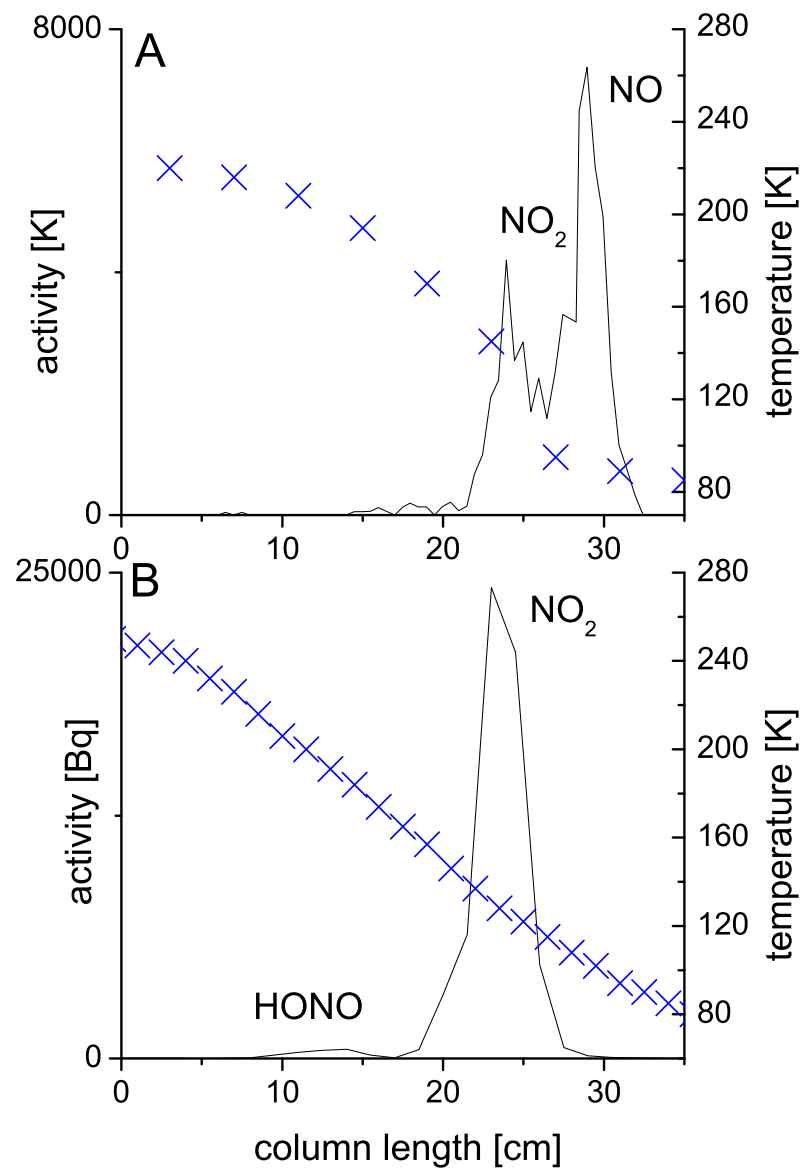

Fig. 5. Comparison of two chromatograms with different experimental conditions. The activity is given on the left axis (solid line) and the temperature along the column at the right axis (crosses). In experiment $\mathrm{A}$ the temperature was always too low for a quasi-liquid layer to form, whereas in chromatogram $\mathrm{B}$ a quasi liquid layer might have evolved. Note that the two $\mathrm{NO}_{2}$ peaks should be compared; the NO in experiment A was added on purpose, without any relation to this comparison.

Dimerisation on the surface can be ruled out under the chosen experimental conditions, based on the symmetry of the

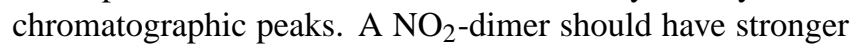
adsorption energies compared to $\mathrm{NO}_{2}$ on the ice surface. Thus dimerisation of $\mathrm{NO}_{2}$ on the surface would result in a fronting of the chromatographic peaks. From the absence of such fronting (see Fig. 3), we conclude that the nitrogen oxides did not dimerize on the surface, nor react to $\mathrm{N}_{2} \mathrm{O}_{3}$. And from the calculations above, we conclude that $\mathrm{NO}_{2}$ did not dimerize in the gas phase and thus the adsorption properties of $\mathrm{NO}_{2}$-monomers were investigated.

Secondly, which are the processes that determined the retention of the nitrogen oxides in the column? For $\mathrm{HNO}_{3}, \mathrm{HONO}$ and PAN, the retention of which is increased at temperatures above $160 \mathrm{~K}$, a metastable, molecular adsorbed state of these adsorbates on the ice surface $\left(\mathrm{NO}_{\mathrm{y}}(\mathrm{ads})\right)$ is assumed. Such a molecular adsorbed state has been proposed for $\mathrm{HCl}$ by Svanberg et al. (2000) based on molecular dynamics simulations. In a subsequent step, the adsorbates may form encapsulated hydrates $\left(\mathrm{NO}_{\mathrm{y}}(\mathrm{aq})\right)$ within the outermost water bilayer (Delzeit et al., 1997), which in the case of the acids facilitates dissociation (Packer and Clary, 1995). Recent molecular dynamic simulations by Bolton and Pettersson (2000) confirmed that the ice surface is highly dynamic at temperatures above $180 \mathrm{~K}$ and indicated that water molecules rapidly exchange between the upper surface layers. The time scale of water molecule exchange is in the order of ns, and thus much faster than the species' residence time on the surface, which is in the order of ms. Hence, we presume that in our experiments not the hydrate formation and dissociation, but the adsorption equilibrium of the molecular species is rate limiting the transport of $\mathrm{HNO}_{3}, \mathrm{HONO}$ and PAN through the column. The dissociation of acids on ice surfaces, the products of which have been experimentally observed for $\mathrm{HNO}_{3}$ by Zondlo et al. (1997), may also rapidly and reversibly occur directly on the surface (Svanberg et al., 2000; Clary and Wang, 1997), and thus again not contribute to the retention of $\mathrm{HNO}_{3}$ and $\mathrm{HONO}$ in the column.

In contrast, we assume that $\mathrm{NO}$ and $\mathrm{NO}_{2}$ are exposed to a rather rigid ice surface, as their retention is only enhanced at temperatures below $140 \mathrm{~K}$, and consequently both are not encapsulated by water molecules. Indeed, Uras et al. found molecular $\mathrm{HCl}$ at low coverage at $125 \mathrm{~K}$ (1998) and showed in a monte carlo simulation that at $110 \mathrm{~K}, \mathrm{NH}_{3}$ stays on the ice surface at low coverage and only builds a hydrate capsule within a surface bilayer at high coverage (Uras et al., 2000).

A quasi-liquid layer has been observed at ice surfaces above $-24^{\circ} \mathrm{C}$ (Bluhm and Salmeron, 1999; Döppenschmidt et al., 1998), and has been used to explain an increased uptake at temperatures approaching the melting point of chemically different species such as NO (Sommerfeld et al., 1992), $\mathrm{HNO}_{3}$ (Diehl et al., 1998) and $\mathrm{SO}_{2}$ (Lamb and Clapsaddle, 1989) . Although in some of the experiments presented here the nitrogen oxides were exposed to ice at temperatures above $-24^{\circ} \mathrm{C}$ at the column entrance, the retention is not influenced by diffusion in the quasi-liquid layer. This is illustrated in Fig. 5, which shows two chromatograms under different experimental conditions. Similar migration distances of $\mathrm{NO}_{2}$ were recorded, even when the column entrance was kept at a temperature too low for a quasi-liquid layer to evolve (Fig. 5a). Obviously, the equilibrium $\mathrm{NO}_{\mathrm{y}}$ (ads) $\rightleftharpoons$ $\mathrm{NO}_{\mathrm{y}}$ (qll) shifts so rapidly that the rate limiting factor for transport of the species along the column remains the adsorption equilibrium $\mathrm{NO}_{\mathrm{y}}$ (gas) $\rightleftharpoons \mathrm{NO}_{\mathrm{y}}$ (ads). The very small fraction taken up into the quasi-liquid layer, which has not been detected within the relatively short duration of the experiments, did not affect the retention of the molecules. Nevertheless, uptake into the quasi-liquid layer might influence the long-term fate of these species.

For polycrystalline ice, as used here, an increased uptake 
Table 1. Adsorption enthalpy , $\Delta \mathrm{H}_{\mathrm{ads}}\left[\mathrm{kJ} \mathrm{mol}^{-1}\right]$, and standard adsorption entropies, $\Delta S_{\text {ads }}^{0}[\mathrm{~J} /(\mathrm{K} \mathrm{mol})]$, of various $\mathrm{NO}_{\mathrm{y}}$ species. Random errors, $\sigma$ [ $\left.\mathrm{kJ} \mathrm{mol}^{-1}\right]$; number of measurements (in brackets) and the systematic error, $\delta_{\text {sys }}\left[\mathrm{kJ} \mathrm{mol}^{-1}\right]$, of $\Delta \mathrm{H}_{\mathrm{ads}}$ are given as well. For calculation of $\Delta S_{\text {ads }}^{01}$ a value of $1 \mathrm{~cm}^{-1}$ for $A / V$ was used and for $\Delta \mathrm{S}_{\mathrm{ads}}^{02}$, A was set to $6.7 \times 10^{10} \mathrm{~cm}^{2}$ and $\mathrm{V}$ to $2.2 \times 10^{4} \mathrm{~cm}^{3}$

\begin{tabular}{|c|c|c|c|c|c|c|}
\hline & $\Delta \mathrm{H}_{\mathrm{ads}}$ & $\sigma$ & $\delta_{\text {sys }}$ & $\Delta S_{\mathrm{ads}}^{01}$ & $\Delta \mathrm{S}_{\mathrm{ads}}^{02}$ & $\sigma$ \\
\hline $\mathrm{HNO}_{3}$ & -44 & $2.3 \quad$ (4) & 13 & -168 & -44 & 0.1 \\
\hline HONO & -32 & 1.7 (9) & 10 & -166 & -42 & 0.1 \\
\hline PAN & -30 & $1.2 \quad(7)$ & 7 & -169 & -45 & 0.5 \\
\hline $\mathrm{NO}_{2}$ & -22 & $1.0(21)$ & 6 & -165 & -39 & 0.1 \\
\hline $\mathrm{NO}$ & -20 & $2.6 \quad(7)$ & 5 & -164 & -40 & 0.2 \\
\hline
\end{tabular}

at warmer temperatures has been explained by diffusion into the grain boundaries (Huthwelker et al., 2001). In addition, strong acids are known to accumulate in the grain boundaries, as Mulvaney et al. (1988) has shown for $\mathrm{H}_{2} \mathrm{SO}_{4}$. This diffusive process is driven by a strong concentration gradient, and as equilibrium is only reached after hours (Mader, 1992), any nitrogen oxide that diffuses into the grain boundaries is trapped in the vein system, at least for the duration of the experiment and thus does not contribute to the peak formation. Furthermore, we note that the surface of the polycrystalline spheres not only consisted of crystalline facies but also of grain boundaries, so that the adsorption enthalpy derived represents an average over all facies, defect sites and grain boundaries exposed at the surface.

In conclusion, we suggest that the retention of each individual nitrogen oxide solely depends on molecular adsorption processes and thus the theory of thermo-chromatography can be applied to our results. We want to state that our current adsorption model does not include changes of the ice surface that are induced by the adsorbate such as restructuring of the ice lattice or vibrational changes (Delzeit et al., 1996).

\subsection{Standard states}

Table 1 shows the adsorption enthalpy of the nitrogen oxides examined. To determine the adsorption enthalpy based on the experimental findings, the standard adsorption entropy was calculated. The standard adsorption entropy calculations were done with two different standard states, which both resulted, as expected, in the same adsorption enthalpy. Recall, that the enthalpy does not depend on the choice of standard states (Carmichael, 1976). There have been two standard states applied for this work, because for adsorption processes there is no general agreement on the choice of a standard state as for pure gas phase processes. In the literature, two different approaches are usually considered. Eichler and Zvára (1982) arbitrarily set the ratio of $\mathrm{A} / \mathrm{V}$ to the value $1 \mathrm{~cm}^{-1}$. The advantage of this standard state is its
Table 2. Assessment of the absolute systematic error, $\delta_{\text {sys }}\left[\mathrm{kJ} \mathrm{mol}^{-1}\right]$. The table lists the modification of a number of input values and the resulting change in $\Delta \mathrm{H}_{\mathrm{ads}}$ for each nitrogen oxide

\begin{tabular}{|c|c|c|c|c|c|c|}
\hline & & NO & $\mathrm{NO}_{2}$ & HONO & $\mathrm{HNO}_{3}$ & PAN \\
\hline$t_{e}$ & $\pm 1 \min$ & 0.1 & 0.0 & 0.1 & 0.1 & 0.1 \\
\hline $\mathrm{u}_{0}$ & $\pm 20 \mathrm{~cm}^{3} \mathrm{~s}^{-1}$ & 0.1 & 0.3 & 0.3 & 0.1 & 0.3 \\
\hline g & $\pm 0.5 \quad \mathrm{~K}$ & 0.1 & 0.1 & 0.1 & 0.2 & 0.1 \\
\hline $\mathrm{v}$ & $\pm 300 \%$ & 1.4 & 1.8 & 1.9 & 2.8 & 1.9 \\
\hline $\mathrm{a}$ & $\pm 300 \%$ & 1.1 & 1.6 & 5.2 & 2.2 & 5.2 \\
\hline $\mathrm{T}_{\mathrm{S}}$ & $+30 \mathrm{~K}$ & 0.0 & 0.0 & 0.1 & 3.0 & 0.0 \\
\hline $\mathrm{T}_{\mathrm{D}}$ & $\pm 10 \mathrm{~K}$ & 1.8 & 2.7 & 2.5 & 4.2 & 2.8 \\
\hline $\mathrm{m}$ & $+1 \mathrm{~g} \mathrm{~mol}^{-1}$ & 0.0 & 0.0 & 0.0 & 0.0 & 0.0 \\
\hline
\end{tabular}

independence of temperature, particle size, and absolute values of V or A. Goss (1997) used a standard state introduced by de Boer (1968), treated the adsorbed species as a two dimensional gas and defined the standard state of that "gas" as a state where the average distance of two molecules is identical to the average distance of two molecules in a three dimensional gas phase at standard pressure and temperature. The two dimensional gas law with a two dimensional pressure $\mathrm{f}\left[\mathrm{N} \mathrm{m}^{-1}\right]$ was used to calculate a standard surface area of $6.7 \times 10^{10} \mathrm{~cm}^{2}(\mathrm{~A})$ in analogy to the standard volume of the gas phase of $2.2 \times 10^{4} \mathrm{~cm}^{3}(\mathrm{~V})$.

Note that the equilibrium constant $K_{p}$ depends on the chosen standard state as well. Equation (5) gives the relation to transfer one into the other, where $\mathrm{a} / \mathrm{v}$ is the actual surface to volume ratio in the experimental set-up; see Appendix B for further information.

$\frac{a}{v} \cdot \frac{2.2 \times 10^{4}}{6.7 \times 10^{10}} \cdot K_{p}^{01}=\frac{a}{v} \cdot 1 \cdot K_{p}^{02}$

\subsection{Error calculation}

Typically, the resulting $\Delta \mathrm{H}_{\mathrm{ads}}$ of several experiments showed a standard deviation of about $1 \%$ to $3 \%$ distributed about the mean. From the experimental set-up presented above, it is evident that systematic errors are the main source of uncertainty. To assess this error, calculations based on one particular experiment have been repeated with all factors changed one by one to their possibly largest extent of uncertainty (Table 2). The resulting total difference in $\Delta \mathrm{H}_{\mathrm{ads}}$ to the mean value, which varies between $23 \%$ and $33 \%$, is given in Table 1 as the total error. These total errors are similar to published uncertainties of experiments on adsorption in flow tubes (Fenter et al., 1996).

It can be clearly seen in Table 2 that the most critical input values are those relying on the determination of the deposition temperature and the ice surface (open volume and surface area). The error in the determination of the deposition temperature results mainly from installing the column manu- 


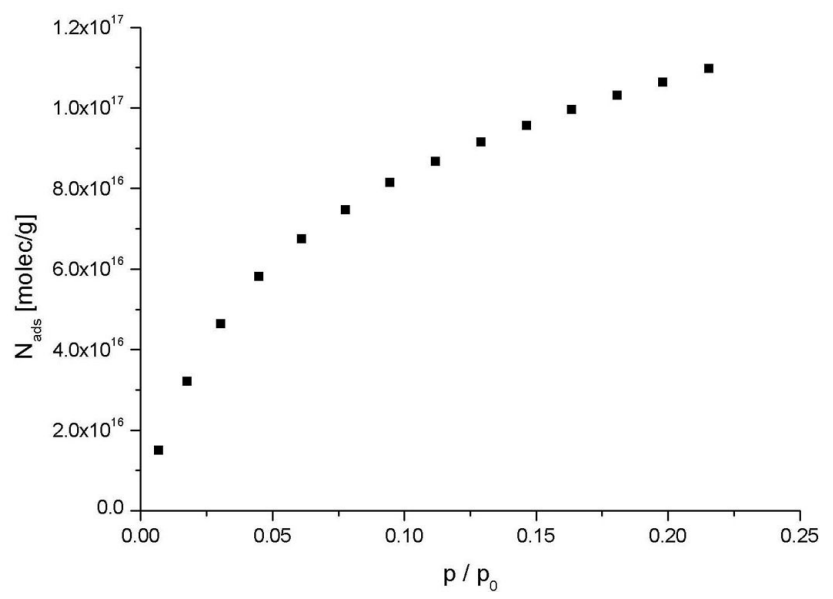

Fig. 6. Methane adsorption isotherm of ice spheres uses in this study.

ally onto the scanner and the resulting inaccuracy of the zero point alignment. Furthermore, the temperature measurement itself might include some error.

The surface areas calculated based on the weight of 100 droplets agreed well with the determination of the radius by sieving. BET measurements of the ice were done to evaluate whether the surface area that is available to adsorption, is of the same size as the geometric surface area. The geometric surface area is the area of a sphere with the same volume as the ice spheres used in our work. In the literature, a discrepancy of up to 8 times larger BET surface area per gram sample compared to the external surface area assessed via ESEM pictures has been observed for ice condensed from the vapor phase (Keyser and Leu, 1993). Figure 6 shows a plot of the methane adsorption isotherm of $66.3 \mathrm{~g}$ ice spheres, which where between 400 and $500 \mu \mathrm{m}$ in diameter. The ice spheres were produced in the same way as the spheres used in the chromatographic experiments. The BET surface area of $0.0186 \mathrm{~m}^{2} \mathrm{~g}^{-1}$ compares perfectly well with the geometric surface area between 0.0121 and $0.0188 \mathrm{~m}^{2} \mathrm{~g}^{-1}$. The geometric surface areas were calculated considering a radius of 400 microns and a density of 0.8 and 500 microns and a density of 0.99 , respectively. Thus we conclude, that the ice spheres' surface area is not enlarged due to pores or additional microstructures on the surface, and the geometric surface area was used for calculations. Any defects that might have evolved due to the fast freezing of the ice, have probably vanished during the crystallization process at $258 \mathrm{~K}$, or do not influence the adsorption properties of the ice surface. Nevertheless, a high error of $300 \%$ was introduced to account for the numerous unknowns such as bulk density of the produced ice, packing density of the column and the accuracy of the method to determine the weight of 100 droplets.

\section{Discussion of the adsorption enthalpy}

Both $\mathrm{NO}$ and $\mathrm{NO}_{2}$ migrate to a temperature of below $140 \mathrm{~K}$ in the column and consequently small adsorption enthalpies of $-20 \mathrm{~kJ} \mathrm{~mol}^{-1}$ and $-22 \mathrm{~kJ} \mathrm{~mol}^{-1}$ are derived. In agreement with the experiments presented here, Saastad et al. (1993) did not detect any loss of NO in the gas phase above ice frozen from the liquid at temperatures down to $193 \mathrm{~K}$. In contrast, Sommerfeld et al. (1992) found an adsorption enthalpy of $-11 \mathrm{~kJ} \mathrm{~mol}^{-1}$ by measuring adsorption isotherms in packed columns down to $200 \mathrm{~K}$ using a chromatographic fronting technique. This discrepancy however might be due to the different experimental method and, as Sommerfeld et al. mentioned, a large uncertainty in their measured loss of NO to the ice, as the loss was small compared to the huge background loss of $\mathrm{NO}$ on the apparatus' walls. The results of $\mathrm{NO}_{2}$ adsorption on ice again agree well with findings of Saastad et al. (1993), as in both cases $\mathrm{NO}_{2}$ did not measurably adsorb on ice at temperatures down to $193 \mathrm{~K}$. Rieley et al. (1996) measured a desorption enthalpy for $\mathrm{N}_{2} \mathrm{O}_{4}$ on ice of $39 \mathrm{~kJ} \mathrm{~mol}^{-1}$, which is higher than the enthalpy of $\mathrm{NO}_{2}$ presented here due to expected stronger binding interactions.

The adsorption of HONO on the ice surface begins to slow down the migration process at temperatures below $170 \mathrm{~K}$, which qualitatively agrees well with a reversible adsorption of HONO at temperatures of $180-200 \mathrm{~K}$ published by Fenter and Rossi (1996). In addition, the HONO adsorption enthalpy of $-32 \mathrm{~kJ} \mathrm{~mol}^{-1}$ is in excellent agreement with an adsorption enthalpy of $-33.8 \mathrm{~kJ} \mathrm{~mol}^{-1}$ reported by Chu et al. (2000).

In all $\mathrm{HNO}_{3}$ experiments in this work, two peaks evolved (see Fig. 3e). The first peak is assigned to an irreversible inclosure of $\mathrm{HNO}_{3}$ in the water rime. The riming was only observed in the experiments with $\mathrm{HNO}_{3}$ because we had to work at higher relative humidity to generate $\mathrm{HNO}_{3}$ from the reaction of $\mathrm{NO}_{2}$ with $\mathrm{OH}$ on-line. The deposition temperatures of the second peak, which were below $245 \mathrm{~K}$, were taken to evaluate the $\mathrm{HNO}_{3}$ adsorption enthalpy of $-44 \mathrm{~kJ} \mathrm{~mol}^{-1}$. Tabazadeh et al. (1999) published a free enthalpy $(\Delta \mathrm{G})$ of $-59.4 \mathrm{~kJ} \mathrm{~mol}^{-1}$ for $\mathrm{HNO}_{3}$ adsorption and dissociation on ice based on experiments by Abbatt (1997). An adsorption enthalpy or entropy has not been published by the authors. If we expect the entropy to be negative due to the reduced degrees of freedom of the adsorbed state compared to the gas phase molecule, the enthalpy should be $\leqslant-60 \mathrm{~kJ} \mathrm{~mol}^{-1}$. This value agrees well with the sublimation enthalpy of $\mathrm{HNO}_{3}$ on ice measured by Thibert and Dominé (1998) of $68 \mathrm{~kJ} \mathrm{~mol}^{-1}$. Both values are as expected more negative than our findings, as they describe enthalpy of both, adsorption and solvation.

The adsorption enthalpy of PAN on ice was determined to be $-30 \mathrm{~kJ} \mathrm{~mol}^{-1}$. To our knowledge the adsorption properties of PAN have been investigated for the first time.

The magnitude of the adsorption enthalpies for nitrogen oxides found point to the formation of one to two hydrogen 


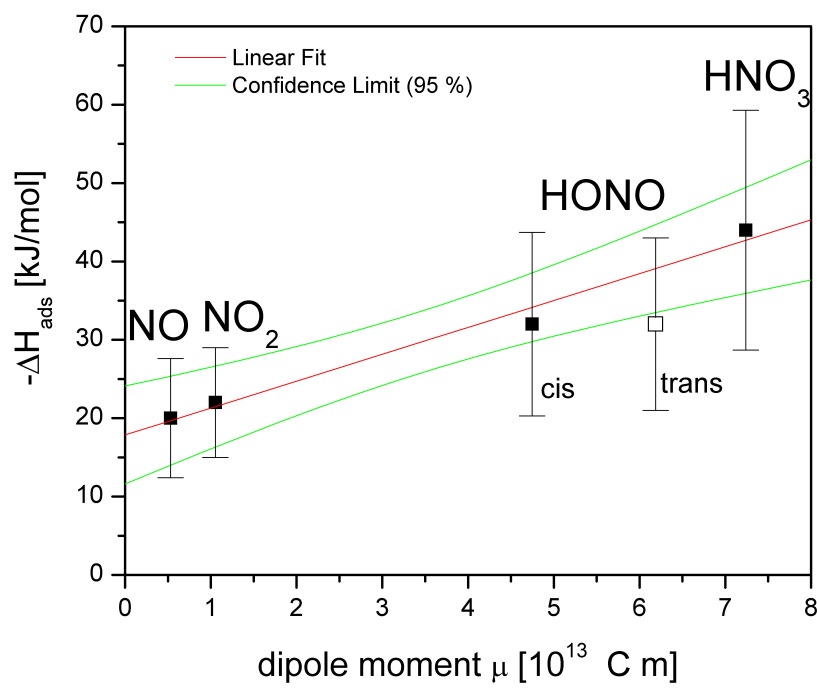

Fig. 7. Correlation of dipole moment (Lide, 2001-2002) and the experimentally found adsorption enthalpy for $\mathrm{NO}, \mathrm{NO}_{2}, \mathrm{HONO}$ and $\mathrm{HNO}_{3}$.

bonds. The strength of a hydrogen bond depends on the capability of an ice surface to act as hydrogen bond donor and the dipole moment of the nitrogen oxide. The capability of the crystalline ice used in this study to form hydrogen bonds, which is determined by the number of free $\mathrm{OH}$ groups on the surface, should be sufficient for the coverage of nitrogen oxides below a mono layer in this work. First of all, FTIRAS measurements indicated a free $\mathrm{OH}$ coverage on crystalline ice to be approximately one-sixth of that on amorphous ice (Schaff and Roberts, 1996). And secondly, even after annealing at $258 \mathrm{~K}$ the polycrystalline character of the ice spheres used in our work, whose grain boundaries might posses free $\mathrm{OH}$ groups, is preserved. Finally, despite the annealing, surface defects facilitating free $\mathrm{OH}$ groups might be present on the surface. Assuming that hydrogen bonding is relevant for adsorption of nitrogen oxides on ice, the overall bond strength of the molecules to the surface should scale with the dipole moment. Figure 7 shows a correlation of dipole moments and the adsorption enthalpy determined in this study.

\section{Atmospheric implications}

Table 3 shows the partitioning of nitrogen oxides between ice and air at temperature and surface to volume ratios present in the environment. To calculate the partitioning coefficient (see Eq. A1) at environmental conditions, the standard Gibbs adsorption energy $\left(\Delta \mathrm{G}_{\mathrm{ads}}^{0}\right)$ was calculated at the temperature of interest based on the adsorption enthalpy and standard adsorption entropy from this study (see Eq. A4). The standard Gibbs adsorption enthalpy was in the following transferred to the partitioning coefficient using the actual surface to vol-
Table 3. Partitioning coefficient, $\mathrm{k}_{\mathrm{i}}$, of nitrogen oxides between ice and air under different atmospheric conditions. Note that the displayed partitioning coefficients describe the equilibrium of the gaseous and molecular adsorbed species. Any secondary equilibrium, such as dissociation, is not included in these calculations. See text for further explanation and references

\begin{tabular}{|c|c|c|c|}
\hline & $\begin{array}{c}\text { temperature } \\
{[\mathrm{K}]}\end{array}$ & $\begin{array}{c}\text { ice area } \\
{\left[\mathrm{cm}^{2} \mathrm{~cm}^{-3}\right]}\end{array}$ & $\begin{array}{c}\mathrm{k}_{\mathrm{i}} \\
{[-]}\end{array}$ \\
\hline & \multicolumn{3}{|c|}{ contrails } \\
\hline $\begin{array}{l}\mathrm{NO} \\
\mathrm{NO}_{2} \\
\mathrm{HONO} \\
\mathrm{PAN} \\
\mathrm{HNO}_{3}\end{array}$ & $\begin{array}{l}213 \\
213 \\
213 \\
213 \\
213\end{array}$ & $\begin{array}{c}1 \times 10^{-2} \\
1 \times 10^{-2} \\
1 \times 10^{-2} \\
1 \times 10^{-2} \\
1 \times 10^{-2} \\
\text { cirrus clouds }\end{array}$ & $\begin{array}{l}2 \times 10^{-6} \\
6 \times 10^{-6} \\
2 \times 10^{-3} \\
3 \times 10^{-4} \\
1\end{array}$ \\
\hline $\begin{array}{l}\mathrm{NO} \\
\mathrm{NO}_{2} \\
\mathrm{HONO} \\
\text { PAN } \\
\mathrm{HNO}_{3}\end{array}$ & $\begin{array}{l}213 \\
213 \\
213 \\
213 \\
213\end{array}$ & $\begin{array}{c}3 \times 10^{-3} \\
3 \times 10^{-3} \\
3 \times 10^{-3} \\
3 \times 10^{-3} \\
3 \times 10^{-3} \\
\text { pack (polar z }\end{array}$ & $\begin{array}{l}7 \times 10^{-7} \\
2 \times 10^{-6} \\
5 \times 10^{-4} \\
1 \times 10^{-4} \\
3 \times 10^{-1}\end{array}$ \\
\hline $\begin{array}{l}\mathrm{NO} \\
\mathrm{NO}_{2} \\
\mathrm{HONO} \\
\mathrm{PAN} \\
\mathrm{HNO}_{3}\end{array}$ & $\begin{array}{l}246 \\
246 \\
246 \\
246 \\
246\end{array}$ & $\begin{array}{l}20 \\
20 \\
20 \\
20 \\
20\end{array}$ & $\begin{array}{l}1 \times 10^{-3} \\
3 \times 10^{-3} \\
3 \times 10^{-1} \\
8 \times 10^{-2} \\
9 \times 10^{+1}\end{array}$ \\
\hline & \multicolumn{3}{|c|}{ snow pack (temperate zone) } \\
\hline $\begin{array}{l}\mathrm{NO} \\
\mathrm{NO}_{2} \\
\mathrm{HONO} \\
\mathrm{PAN} \\
\mathrm{HNO}_{3}\end{array}$ & $\begin{array}{l}268 \\
268 \\
268 \\
268 \\
268\end{array}$ & $\begin{array}{l}70 \\
70 \\
70 \\
70 \\
70\end{array}$ & $\begin{array}{l}2 \times 10^{-3} \\
3 \times 10^{-3} \\
3 \times 10^{-1} \\
7 \times 10^{-2} \\
4 \times 10^{+1}\end{array}$ \\
\hline
\end{tabular}

ume ratio in the environment and the chosen standard state of the entropy calculation (see Eq. A3).

To illustrate the possible influence of adsorption of nitrogen oxides on the gas phase concentrations of $\mathrm{NO}_{\mathrm{x}}$ (see Fig.4), these back-of-the-envelope calculations were performed with a wide range of environmental conditions. Namely, a high concentration of ice particles of up to $200 \mathrm{~cm}^{-3}$ typically found in contrails (Schröder et al., 2000), a huge surface area of freshly fallen snow in the arctic and temperate zone (Dominé et al., 2001) or the cold temperatures in the upper troposphere and the typical surface to volume ratio in the clouds (Schröder et al., 2000) were taken. 
For a detailed description additional factors, such as gas phase and ice diffusion, or additional equilibria following the adsorption have to be included in a more precise model calculation, which is beyond the scope of this work. Nevertheless this basic estimation shows that $\mathrm{HNO}_{3}$ significantly partitions to the ice phase where ice is abundant, whereas NO and $\mathrm{NO}_{2}$ do not at all. $\mathrm{HONO}$ and PAN might not partition to the ice phase in clouds, but are expected to do so in the snow pack. As the partition coefficient strongly changes with temperature (e.g. for HONO $\mathrm{k}_{\mathrm{i}} \approx 1$ at $230 \mathrm{~K}$ and $\mathrm{k}_{\mathrm{i}} \approx 3 \times 10^{-1}$ at $250 \mathrm{~K}$ in an arctic environment) emission from or deposition to the snow pack may be expected after strong temperature changes. Be aware that these calculations might underestimate the total uptake on ice, as they do not account for additional processes, which follow the adsorption process and thus continuously shift the adsorption equilibrium.

\section{Conclusions}

The retention of nitrogen oxides fed to a chromatographic column filled with ice spheres in synthetic air or nitrogen was investigated at atmospheric pressure and submonolayer coverage. It was argued that the retention was exclusively determined by the equilibrium between a gas phase and a molecularly adsorbed species and not influenced by dimerisation, formation of an encapsulated hydrate on the ice surface, dissociation of the acids, nor by migration into a quasi-liquid layer or grain boundaries.

Based on the migration distance of each nitrogen oxide in the column, the enthalpy for molecular adsorption of $-20 \mathrm{~kJ} \mathrm{~mol}^{-1}$ for $\mathrm{NO},-22 \mathrm{~kJ} \mathrm{~mol}^{-1}$ for $\mathrm{NO}_{2},-30 \mathrm{~kJ} \mathrm{~mol}^{-1}$ for peroxyacetyl nitrate, $-32 \mathrm{~kJ} \mathrm{~mol}^{-1}$ for $\mathrm{HONO}$ and $-44 \mathrm{~kJ} \mathrm{~mol}^{-1}$ for $\mathrm{HNO}_{3}$ was calculated. To perform these calculations, a standard state had to be chosen. The adsorption enthalpy values derived proved to be independent of that choice, and is thus an ideal value for comparison of adsorption energies with other groups. An error analysis revealed the actual surface area of the ice as major source of systematic uncertainty of the adsorption enthalpy calculations. Nevertheless, the total error associated with the reported adsorption enthalpy is less than $33 \%$.

A brief outlook on environmental implications of our findings for exemplary conditions in contrails, cirrus clouds, as well as arctic and temperate zone snow packs indicated that adsorption on ice might be an important removal process of $\mathrm{HNO}_{3}$, of some importance for $\mathrm{HONO}$ and peroxyacetyl nitrate and irrelevant for $\mathrm{NO}$ and $\mathrm{NO}_{2}$.

Acknowledgements. The authors thank E. Rössler, M. Birrer and D. Piguet for continuing support of our work, L. Legagneux and F. Dominé for help on BET - measurements at the CNRS, and the staff of PSI Accelerator Facilities for the beam generation. This work is part of the EU project CUT-ICE (EVK2 - CT1999 - 00005) funded by the Swiss Federal Office for Education and Science (99.00491-2). We would also like to thank all CUT-ICE partners for the discussions during the CUT-ICE meetings.

\section{Appendix A: Notation}

\begin{tabular}{|c|c|c|}
\hline Symbol & Explanation & Unit \\
\hline$S$ & entropy & $\mathrm{J}\left(\mathrm{K} \mathrm{mol}^{-1}\right)$ \\
\hline$H$ & enthalpy & $\mathrm{J}\left(\mathrm{K} \mathrm{mol}^{-1}\right)$ \\
\hline$U$ & inner energy & $\mathrm{J}\left(\mathrm{K} \mathrm{mol}^{-1}\right)$ \\
\hline$U(0)$ & zero inner energy & $\mathrm{J}\left(\mathrm{K} \mathrm{mol}^{-1}\right)$ \\
\hline$q$ & $\begin{array}{l}\text { molecular partition } \\
\text { function }\end{array}$ & - \\
\hline$Q$ & $\begin{array}{l}\text { molar partition func- } \\
\text { tion }\end{array}$ & - \\
\hline$T$ & temperature & K \\
\hline$T_{\mathrm{D}}$ & $\begin{array}{l}\text { deposition tempera- } \\
\text { ture (temperature at } \\
\text { the position of the } \\
\text { peak) }\end{array}$ & $\mathrm{K}$ \\
\hline$u$ & linear gas velocity & $\mathrm{cm} \mathrm{min}^{-1}$ \\
\hline$u_{0}$ & $\begin{array}{l}\text { linear gas velocity at } \\
\text { standard temperature }\end{array}$ & $\mathrm{cm} \mathrm{min}^{-1}$ \\
\hline$a$ & surface area & $\mathrm{cm}^{2}$ \\
\hline$v$ & volume & $\mathrm{cm}^{3}$ \\
\hline$p$ & pressure & $\mathrm{Nm}^{-2}$ \\
\hline$f$ & $\begin{array}{l}\text { two dimensional } \\
\text { pressure }\end{array}$ & $\mathrm{Nm}^{-1}$ \\
\hline$A$ & standard surface area & $\mathrm{cm}^{2}$ \\
\hline$V$ & standard volume & $\mathrm{cm}^{3}$ \\
\hline$p^{0}$ & standard pressure & $1 \times 10^{5} \mathrm{~N} \mathrm{~m}^{-2}$ \\
\hline$f^{0}$ & $\begin{array}{l}\text { standard two dimen- } \\
\text { sional pressure }\end{array}$ & $3.38 \times 10^{-2} \mathrm{~N} \mathrm{~m}^{-1}$ \\
\hline$M$ & molecular mass & $\mathrm{kg}$ \\
\hline$m$ & molar mass & $\mathrm{kg} \mathrm{mol}^{-1}$ \\
\hline$n$ & number of molecules & - \\
\hline$v$ & vibrating frequency & $\mathrm{s}^{-1}$ \\
\hline$N_{\mathrm{A}}$ & Loschmidt's number & $6.02285 \times 10^{23} \mathrm{~mol}^{-1}$ \\
\hline$k_{\mathrm{B}}$ & Boltzmann constant & $1.38066 \times 10^{-23} \mathrm{~J} \mathrm{~K}^{-1}$ \\
\hline$h$ & Planck constant & $6.62618 \times 10^{-34} \mathrm{~J} \mathrm{~s}$ \\
\hline$R$ & gas constant & $8.31441 \mathrm{~J}(\mathrm{~K} \mathrm{~mol})^{-1}$ \\
\hline
\end{tabular}

\section{Appendix B: Partitioning coefficient, adsorption equilib- rium constant and standard states}

At low concentrations the partitioning of each species in the chromatographic column, or in any two phase system, can be described by the partition coefficient (Eq. A1), which gives a relation of the total number of adsorbed and gaseous species.

$k_{i}=\frac{n^{\mathrm{ads}}}{n^{\mathrm{gas}}}[-]$ 
This partition can be described by the adsorption equilibrium constant, which accounts for the influence of the actual surface to volume ratio on the column (Eq. A2).

$$
\begin{aligned}
& K_{\mathrm{c}}=\frac{n^{\mathrm{ads}} / a}{n^{\mathrm{gas}} / v}[\mathrm{~cm}] \\
& =k_{i} \cdot \frac{v}{a}[\mathrm{~cm}]
\end{aligned}
$$

To perform thermodynamical calculations, the adsorption equilibrium constant $\left(\mathrm{K}_{\mathrm{c}}\right)$ has to be transferred into the dimensionless standard equilibrium constant $\left(\mathrm{K}_{\mathrm{p}}\right)$, as can be seen in Eq. (A3).

$$
\begin{aligned}
K_{\mathrm{p}} & =\frac{f / f^{0}}{p / p^{0}}[-] \\
& =\frac{n^{\mathrm{ads}} / a \cdot R T \cdot p^{0}}{n^{\mathrm{gas}} / v \cdot R T \cdot f^{0}}[-] \\
& =k_{i} \cdot \frac{v}{a} \cdot \frac{A}{V}[-]
\end{aligned}
$$

The advantage of the standard adsorption equilibrium constant $\left(K_{\mathrm{p}}\right)$ is, that it can be expressed in terms of the standard adsorption entropy and adsorption enthalpy (Eq. A4), which both can be regarded as independent of temperature.

$-R T \ln K_{\mathrm{p}}=\Delta H_{\mathrm{ads}}-T \Delta S_{\mathrm{ads}}^{0}$

\section{Appendix C: The transport model and enthalpy calcula- tions}

The calculation of the adsorption enthalpy within the model of thermo-chromatography has been described by Eichler and Zvára (1982) in great detail. The transport of a species along the chromatographic column at low concentrations is given by Eq. (A5).

$\frac{\mathrm{d} z}{\mathrm{~d} t}=\frac{u}{1+k_{i}}$

If a linear temperature gradient along the column (Eq. A6) is given,

$T=T_{\mathrm{s}}-g \cdot z$

Eq. (A5) yields

$t=-\frac{1}{g} \int_{T_{\mathrm{S}}}^{T_{\mathrm{D}}} \frac{1+\frac{a}{v} \cdot \frac{V}{A} K_{\mathrm{p}}(T)}{u(T)} \mathrm{d} T$.

Neglecting the change in gas pressure along the column, we have

$u(T)=\frac{u_{0} \cdot T}{T_{0}}\left[\mathrm{~cm} \mathrm{~s}^{-1}\right]$.

Assuming that $\Delta \mathrm{H}_{\mathrm{ads}}$ and $\Delta \mathrm{S}_{\text {ads }}^{0}$ are independent of temperature, and substituting Eqs. (A3), (A4) and (A8) in Eq. (A7), we obtain Eq. (A9), which can be solved by an iteration process, if $\Delta \mathrm{S}_{\text {ads }}^{0}$ is known.

$$
\begin{aligned}
(t+ & \left.\frac{T_{0}}{g \cdot u_{0}} \cdot \ln \frac{T_{\mathrm{D}}}{T_{\mathrm{S}}}\right) \cdot \frac{v \cdot g \cdot u_{0}}{a \cdot T_{0} \cdot \frac{V}{A} \cdot \exp \left(\frac{\Delta S_{\mathrm{ads}}^{0}}{R}\right)} \\
& =\int_{T_{\mathrm{S}}}^{T_{\mathrm{D}}} \frac{1}{T} \cdot \exp \left(\frac{-\Delta H_{\mathrm{ads}}}{R T}\right)
\end{aligned}
$$

\section{Appendix D: Entropy calculations}

Statistical thermodynamics allow to very precisely calculate the absolute entropy based on the partition functions. In the following we will calculate the change in entropy during adsorption as the difference of the absolute entropy of a molecule in the gas phase and of the molecule in the adsorbed state (Eq. A10).

$\Delta S_{\mathrm{ads}}=S_{\mathrm{ads}}-S_{\mathrm{gas}}$

Each entropy term can be calculated based on the molar partition function, Eq. (A11). Using Stirling's approximation and $R=k_{\mathrm{B}} \cdot N_{\mathrm{A}}$ the partition function can be written as the molecular partition function (Eq. A12) for the canonical ensemble (Eq. A13).

$$
\begin{aligned}
& S=\frac{\{U-U(0)\}}{T}+k_{\mathrm{B}} \cdot \ln Q \\
& S=\frac{\{U-U(0)\}}{T}+n R \cdot \ln \left\{\ln q-\ln N_{\mathrm{A}}+1\right\} \\
& Q=q^{n} / n !
\end{aligned}
$$

The inner energy, U-U(0), can itself be calculated based on the partition functions (Eq. A14).

$$
\begin{array}{r}
U-U(0)=-n \frac{\delta \ln q}{\delta k T} \\
=-n k_{\mathrm{B}} T^{2} \frac{\delta \ln q}{\delta T}
\end{array}
$$

The partition function is simply calculated based on the molecule's translational (trans), rotational (rot), vibrational (vib) and electronical (el) degrees of freedom (Eq. A14).

$q^{\mathrm{tot}}=q^{\mathrm{trans}} \cdot q^{\mathrm{rot}} \cdot q^{\mathrm{vib}} \cdot q^{\mathrm{el}}$

The adsorbed state is defined by a large mobility of the adsorbed molecules on the surface and a vibrating mode perpendicular to the surface. The molecule only loses one translational degree of freedom and gains one vibrational degree of freedom during adsorption. As internal vibrations, rotations and the electronic configuration do not change and thus do not contribute to the adsorption entropy, we can calculate the partition function solely based on the translational and vibrational partition function. The translational partition function is calculated based on a particle-in-the-box as

$q^{\text {trans }}=V \cdot\left(\frac{2 \pi m k_{\mathrm{B}} T}{h^{2}}\right)^{\frac{3}{2}}$ 
for the three dimensional state and as

$q^{\text {trans }}=A \cdot\left(\frac{2 \pi m k_{\mathrm{B}} T}{h^{2}}\right)$

for the two dimensional (adsorbed) state. The vibrational partition function for one mode is given by

$q^{\mathrm{vib}}=\frac{e^{\frac{-h v}{2 k t}}}{1-e^{\frac{h v}{k_{\mathrm{B}} T}}}$.

The vibrating frequency $(v)$ of the molecule in the adsorbed state is considered to be similar to the phonon frequency of ice. Since to our knowledge no experimental data about the vibrating frequency of the solid state of water exist at these temperatures, a rounded value of $3 \times 10^{13} \mathrm{~s}^{-1}$ based on the relations of Madelung and Einstein, Lindemann and Debye and data in Hobbs (1974, p. 388) was used.

Using Eqs.( A14) and (A16) to calculate the contribution of the inner energy to the entropy yields

$\frac{U-U(0)}{T}=\frac{3}{2} k_{\mathrm{B}} N_{\mathrm{A}}$

for the molecules in the gas phase. Similarly, for the adsorbed state based on Eqs. (A14), (A17) and (A18), we get

$$
\begin{gathered}
\frac{U-U(0)}{T}=k_{\mathrm{B}} N_{\mathrm{A}}+k_{\mathrm{B}} N_{\mathrm{A}} \cdot \frac{h v}{2 k_{\mathrm{B}} T} \\
+\frac{N_{\mathrm{A}} k_{\mathrm{B}} \cdot h v}{k_{\mathrm{B}} T \cdot\left(e^{\frac{h v}{k_{\mathrm{B}} T}}-1\right)} .
\end{gathered}
$$

Using Eqs. (A10), (A12), and (A16-A20), we finally get the standard adsorption entropy

$$
\begin{aligned}
\Delta S_{\mathrm{ads}}^{0} & =k_{\mathrm{B}} N_{\mathrm{A}}-\frac{3}{2} k_{\mathrm{B}} N_{\mathrm{A}}+k_{\mathrm{B}} N_{\mathrm{A}} \cdot \frac{h v}{2 k_{\mathrm{B}} T} \\
& +\frac{N_{\mathrm{A}} k_{\mathrm{B}} \cdot h v}{k_{\mathrm{B}} T \cdot\left(e^{\frac{h v}{k_{\mathrm{B}} T}}-1\right)} \\
& +N_{\mathrm{A}} k_{\mathrm{B}}\left[\ln \left(\frac{A}{V} \sqrt{\frac{N_{A} h^{2}}{2 \pi m k_{\mathrm{B}} T}}\right)+\ln e^{-\frac{h v}{2 k_{\mathrm{B}} T}}\right] \\
& -N_{\mathrm{A}} k_{\mathrm{B}} \ln \left(1-e^{-\frac{h v}{k_{\mathrm{B}} T}}\right)
\end{aligned}
$$

and with $\ln \left(1-e^{-\frac{h v}{k_{\mathrm{B}}^{T}}}\right)$ being approximately 0, Eq. (A21) finally yields Eq. (A22), which was used for calculations in this work.

$$
\begin{aligned}
\Delta S_{\mathrm{ads}}^{0} & =R\left[\ln \left[\frac{A}{V} \sqrt{\frac{N_{\mathrm{A}} h^{2}}{2 \pi m k_{\mathrm{B}} T_{\mathrm{D}}}}\right]-0.5\right] \\
& +R\left[\frac{h v}{k_{\mathrm{B}} T_{\mathrm{D}}\left(e^{\frac{h v}{k_{\mathrm{B}} T_{\mathrm{D}}}}-1\right)}\right]
\end{aligned}
$$

\section{References}

Abbatt, J. P.D.: Interaction of $\mathrm{HNO}_{3}$ with water-ice surfaces at temperatures of the free troposphere, Geophys. Res. Letts., 24, 1479-1482, 1997.

Ammann, M.: Using ${ }^{13} \mathrm{~N}$ as tracer in heterogeneous atmospheric chemistry experiments, Radiochimica Acta, 89, 831-838, 2001.

Atkinson, R., Baulch, D. L., Cox, R. A., Hampson, R. F., Kerr, J. A., Rossi, M.J., and Troe, J.: Summary of evaluated kinetic and photochemical data for atmospheric chemistry, http: //www . iupac-kinetic.ch.cam.ac.uk, 1999.

Bluhm, H. and Salmeron, M.: Growth of nanometer thin ice films from water vapor studied using scanning polarization force microscopy, J. Phys. Chem., 111, 6947-6954, 1999.

Bolton, K. and Pettersson, J. B. C.: A molecular dynamics study of the long-time ice Ih surface dynamics, J. Phys. Chem. B, 104, 1590-1595, 2000.

Carmichael, H.: Textbook errors, 125 - what standard state doesn't say about temperature and phase, J. Chem. Edu., 53, 695-695, 1976.

Chu, L., Diao, G., and Chu, L. T., Heterogeneous interaction and reaction of HONO on ice films between 173 and $230 \mathrm{~K}$, J. Phys. Chem. A, 104, 3150-3158, 2000.

Clary, D. C. and Wang, L. C.: Influence of surface defects on the adsorption of $\mathrm{HCl}$ on ice, J. Chem. Society-Faraday Transactions, 93, 2763-2767, 1997.

Conklin, M. H., Sommerfeld, R. A., Laird, S. K., and Villinski, J. E.: Sulfur dioxide reactions on ice surfaces: implications for dry deposition to snow, Atmos. Environ., 27A, 159-166, 1993.

Crutzen, P. J.: The influence of nitrogen oxides on the atmospheric ozone content, Q. J. Roy. Meteo. Soc., 96, 320-325, 1970.

de Boer, J. H.: The Dynamical Character of Adsorption, Clarendon Press, Oxford, 1968.

Delzeit, L., Devlin, M.S., Rowland, B., Devlin, J.P., and Buch, V.: Adsorbate-induced partial ordering of the irregular surface and subsurface of crystalline ice, J. Phys. Chem., 100, 10076 $10082,1996$.

Delzeit, L., Powell, K., Uras, N., and Devlin, J. P.: Ice surface reactions with acids and bases, J. Phys. Chem. B, 101, 2327-2332, 1997.

Diehl, K., Mitra, S. K., and Pruppacher, H. R.: A laboratory study on the uptake of $\mathrm{HCl}, \mathrm{HNO}_{3}$ and $\mathrm{SO}_{2}$ gas by ice crystals and the effect of these gases on the evaporation rate of the crystals, Atmos. Res., 48, 235-244, 1998.

Dominé, F., Cabanes, A., Taillandier, A.-S., and Legagneux, L.: Specific surface area of snow samples determined by $\mathrm{CH}_{4}$ adsorption at $77 \mathrm{~K}$ and estimated by optical microscopy and scanning electron microscopy, Environ. Sci. Tech., 35, 771-780, 2001.

Döppenschmidt, A., Kappl, M., and Butt, H.-J.: Surface properties of ice studied by atomic force microscopy, J. Phys. Chem. B, 102, 7813-7819, 1998.

Eichler, B. and Zvára, I.: Evaluation of the enthalpy of adsorption from thermochromatographical data, Radiochimica Acta, 30, 233-238, 1982.

Eichler, B., Baltensperger, U., Ammann, M., Jost, D., Gäggeler, H., and Türler, A.: Thermochromatographic investigation on ${ }^{13} \mathrm{~N}$ labeled nitrous gases and of fission noble gases at low temperatures, Radiochimica Acta, 68, 41-49, 1995.

Eichler, B., Zimmermann, H. P., and Gäggeler, H.: Adsorption of 
radon on ice surfaces, J. Phys. Chem. A, 104, 3126-3131, 2000.

Fenter, F. F. and Rossi, M. J.: Heterogeneous kinetics of HONO on $\mathrm{H}_{2} \mathrm{SO}_{4}$ solutions and on ice: Activation of $\mathrm{HCl}$, J. Phys. Chem., 100, 13765-13 775, 1996.

Fenter, F.F., Caloz, F., and Rossi, M. J.: Heterogeneous kinetics of $\mathrm{N}_{2} \mathrm{O}_{5}$ uptake on salt, with a systematic study of the role of surface presentation (for $\mathrm{N}_{2} \mathrm{O}_{5}$ and $\mathrm{HNO}_{3}$ ), J. Phys. Chem., 100, 1008-1019, 1996.

Girardet, C. and Toubin, C.: Molecular atmospheric pollutant adsorption on ice: a theoretical survey, Surface Science Reports, 44, 159-238, 2001.

Goss, K.-U.: Conceptual model for the adsorption of organic compounds from the gas phase to liquid and solid surfaces, Environ. Sci. Tech., 31, 3600-3605, 1997.

Heymsfield, A. J. and Sabin, R. M.: Cirrus crystal nucleation by homogeneous freezing of solution droplets, J. Atmos. Res., 46, 2252-2264, 1998.

Hobbs, P. V.: Ice physics, Clarendon Press, Oxford, 1974.

Huthwelker, T., Lamb, D., Baker, M., Swanson, B., and Peter, T.: Uptake of $\mathrm{SO}_{2}$ by polycrystalline water ice, J. Colloid and Interface Science, 238, 174-159, 2001.

Jaeglé, L., Jacob, D. J., Brune, W. H., Tan, D., Faloona, I. C., Weinheimer, A. J., Ridley, B. A., Campos, T.L., and Sachse, G. W.: Sources of $\mathrm{HO}_{\mathrm{x}}$ and production of ozone in the upper troposphere over the United States, Geophys. Res. Letts., 25, 17091712, 1998 .

Kalberer, M., Tabor, K., Ammann, M., Parrat, Y., Weingartner, E., Piguet, D., Rössler, E., Jost, D. T., Türler, A., Gäggeler, H. W., and Baltensperger, U.: Heterogeneous chemical processing of ${ }^{13} \mathrm{NO}_{2}$ by monodisperse carbon aerosols at very low concentrations, J. Phys. Chem., 100, 15 487-15 493, 1996.

Kalberer, M., Ammann, M., Arens, F., Gäggeler, H.W., and Baltensperger, U.: Heterogeneous formation of nitrous acid (HONO) on soot aerosol particles, J. Geophys. Res., 104, 13 825-13 832, 1999.

Keyser, L.F. and Leu, M.-T.: Surface areas and porosities of ices used to simulate stratospheric clouds, J. Colloid and Interface Science, 155, 137-145, 1993.

Lamb, D. and Clapsaddle, C.: The sorption of $\mathrm{SO}_{2}$ on ice at temperatures between $-30^{\circ} \mathrm{C}$ and $-5^{\circ} \mathrm{C}$, Geophys. Res. Letts., 16, $1173-$ 1176, 1989

Legagneux, L., Cabanes, A., and Dominé, F.: Measurement of the specific surface area of 176 snow samples using methane adsorption at 77 K, J. Geophys. Res., in press, 2002.

Lide, D. R.: (Ed) Handbook of Chemistry and Physics, CRC Press, New York, 82 edn., 2001-2002.

Mader, H. M.: The thermal behaviour of the water-vein system in polycrystalline ice, J. Glaciology, 38, 359-374, 1992.

Mulvaney, R., Wolff, E. W., and Oates, K.: Sulphuric acid at grain boundaries in antarctic ice, Nature, 331, 247-249, 1988.

Neuman, J. A., Huey, L. G., Ryerson, T. B., and Fahey, D. W.: Study of inlet materials for sampling atmospheric nitric acid, Environ. Sci. Tech., 33, 1133-1136, 1999.

Packer, M. J. and Clary, D. C.: Interaction of $\mathrm{HCl}$ with water clus- ters: $\left(\mathrm{H}_{2} \mathrm{O}\right)_{\mathrm{n}} \mathrm{HCl}, \mathrm{n}=1-3$, J. Phys. Chem., 99, 14 323-14 333, 1995.

Rieley, H., McMurray, D. P., and Haq, S.: Adsorption and photochemistry of dinitrogen tetroxide on low temperature ice layers, J. Chem. Soc. - Faraday Transactions, 92, 933-939, 1996.

Saastad, O. W., Ellermann, T., and Nielsen, C. J.: On the adsorption of $\mathrm{NO}$ and $\mathrm{NO}_{2}$ on cold $\mathrm{H}_{2} \mathrm{O} / \mathrm{H}_{2} \mathrm{SO}_{4}$ surfaces, Geophys. Res. Letts., 20, 1191-1193, 1993.

Schaff, J. E. and Roberts, J. T.: Toward an understanding of the surface chemical properties of ice: Differences between the amorphous and crystalline surfaces, J. Phys. Chem., 100, $14151-$ 14 160, 1996.

Schrimpf, W., Müller, K.P., Johnen, F. J., Lienaerts, K., and Rudolph, J.: An optimized method for airborne peroxyacetyl nitrate (PAN) measurements, J. Phys. Chem., 22, 303-317, 1995.

Schröder, F., Kärcher, B., Duroure, C., Ström, J., Petzold, A., Gayet, J. F., Strauss, B., Wendling, P., and Borrmann, S.: On the transition of contrails into cirrus clouds, J. Atmos. Sci., 57, 464-480, 2000.

Sommerfeld, R. A., Conklin, M. H., and Laird, S. K.: NO adsorption on ice at low concentrations, J. Colloid and Interface Science, 149, 569-574, 1992.

Svanberg, M., Pettersson, J. B.C., and Bolton, K.: Coupled $\mathrm{QM} / \mathrm{MM}$ molecular dynamics simulations of $\mathrm{HCl}$ interacting with ice surfaces and water clusters - evidence of rapid ionization, J. Phys. Chem. A, 104, 5787-5798, 2000.

Tabazadeh, A., Toon, O. B., and Jensen, E. J.: A surface chemistry model for nonractive trace gas adsorption on ice: Implications for nitric acid scavening by cirrus, Geophys. Res. Letts., 26, 22112214, 1999.

Thibert, E. and Dominé, F.: Thermodynamics and kinetics of the solid solution of $\mathrm{HNO}_{3}$ in ice, J. Phys. Chem. B, 102, 4432 4439, 1998.

Uras, N., Rahman, M., and Devlin, J. P.: Covalent $\mathrm{HCl}$ at the surface of crystalline ice at $125 \mathrm{~K}$ : The stable phase at submonolayer levels, J. Phys. Chem. B, 102, 9375-9377, 1998.

Uras, N., Buch, V., and Devlin, J. P.: Hydrogen bond surface chemistry: Interaction of $\mathrm{NH}_{3}$ with an ice particle, J. Phys. Chem. B, 104, 9203-9209, 2000.

Wang, W.C., Zhuang, Y.C., and Bojkov, R. D.: Climate implications of observed changes in ozone vertical distributions at middle and high latitudes of the northern hemisphere, Geophys. Res. Letts., 20, 1567-1570, 1993.

Warneck, P. and Zerbach, T.: Synthesis of peroxyacetyl nitrate in air by acetone photolysis, Enivon. Sci. Tech., 26, 74-79, 1992.

Weinheimer, A. J., Campos, T. L., Walega, J. G., Grahek, F. E., Ridley, B. A., Baumgardner, D., Twohy, C.H., Gandrud, B., and Jensen, E. J.: Uptake of $\mathrm{NO}_{\mathrm{y}}$ on wave cloud ice particles, Geophys. Res. Letts., 25, 1725-1728, 1998.

Winkler, D. M. and Trepte, C. E.: Laminar cirrus observed near the tropical tropopause by LITE, Geophys. Res. Letts., 25, 33513354, 1998.

Zondlo, M. A., Barone, S. B., and Tolbert, M. A.: Uptake of $\mathrm{HNO}_{3}$ on ice under tropospheric conditions, Geophys. Res. Letts., 24 1391-1394, 1997. 